\title{
Retinoblastoma protein (RB) interacts with E2F3 to control terminal differentiation of Sertoli cells
}

\author{
E Rotgers ${ }^{1,2}$, A Rivero-Müller ${ }^{1}$, M Nurmio ${ }^{1,2}$, M Parvinen ${ }^{1}$, F Guillou $^{3}$, I Huhtaniemi ${ }^{1,4}$, N Kotaja ${ }^{1}$, S Bourguiba-Hachemi ${ }^{1,5,6}$ \\ and J Toppari ${ }^{\star, 1,2,6}$
}

The retinoblastoma protein (RB) is essential for normal cell cycle control. RB function depends, at least in part, on interactions with the E2F family of DNA-binding transcription factors (E2Fs). To study the role of RB in the adult testis, a Sertoli cell (SC)-specific Rb knockout mouse line (SC-RbKO) was generated using the Cre/loxP recombination system. SC-RbKO mice exhibited an age-dependent testicular atrophy, impaired fertility, severe SC dysfunction, and spermatogenic defects. Removal of $R b$ in SC induced aberrant SC cycling, dedifferentiation, and apoptosis. Here we show that E2F3 is the only E2F expressed in mouse SCs and that RB interacts with E2F3 during mouse testicular development. In the absence of RB, the other retinoblastoma family members p107 and p130 began interacting with E2F3 in the adult testes. In vivo silencing of E2F3 partially restored the SC maturation and survival as well as spermatogenesis in the SC-RbKO mice. These results point to RB as a key regulator of SC function in adult mice and that the RB/E2F3 pathway directs SC maturation, cell cycle quiescence, and RB protects SC from apoptosis.

Cell Death and Disease (2014) 5, e1274; doi:10.1038/cddis.2014.232; published online 5 June 2014

Subject Category: Experimental Medicine

The retinoblastoma protein $(\mathrm{RB})$ is a central orchestrator of key cellular events, such as cell cycle control, differentiation, apoptosis, chromosome stability, and chromatin structure. Briefly, RB regulates $\mathrm{G} 1$ to $\mathrm{S}$ transition in the cell cycle, and consequently loss of RB function in mammalian cells is frequently associated with unrestrained and aberrant proliferation. Even though RB is a key regulator of cell cycle, it does not function in isolation. RB-E2F complexes provide a mechanism to control the temporal expression of genes that are needed for cell proliferation, development, apoptosis, and cell survival. (reviewed in Classon and Harlow ${ }^{1}$ and Burkhart and $\mathrm{Sage}^{2}$ ). During G1/S transition of the cell cycle, cyclin D/cyclin-dependent kinases 4/6 complexes hyperphosphorylate RB causing RB to dissociate from E2F transcription factors. As a result, free E2F activates genes that allow $S$ phase progression. In addition, RB activates transcription of genes required for cell cycle exit and the onset of differentiation by interacting with various differentiation-specific transcription factors, such as MyoD (reviewed in Yan et al. ${ }^{3}$ ). The distinct expression and phosphorylation profile of RB during rat testicular development and spermatogenesis suggests that $\mathrm{RB}$ is involved in the regulation of spermatogonial proliferation and Sertoli cell (SC) differentiation. ${ }^{4} R b$-null mice die by embryonic day (E) $15.5,{ }^{5}$ preventing further in vivo study of the role of $\mathrm{RB}$ in later stages of testis development.

SC are central controllers of early testicular differentiation, male sexual development, and germ cell differentiation in adult life. As unique somatic cells that reside within the seminiferous epithelium of the testis, they provide physical and metabolic support for germ-cell differentiation, meiosis and transformation into spermatozoa. At puberty, SC cease to proliferate, change their morphology and function, and establish the blood-testis barrier (BTB) as they undergo maturation. Thus, defective SC maturation, function, or development causes disorders in spermatogenesis (reviewed in Sharpe et al. ${ }^{6}$ ) and is associated with impaired semen quality and testis cancer. ${ }^{7}$ Although mammalian spermatogenesis is completely dependent on the long-term survival of SC, little is known about the mechanisms that sustain this non-renewable cell population through adult life. RB has been shown to be a key regulator of cell cycle exit during SC terminal differentiation, and ablation of RB leads to progressive disruption of spermatogenesis. ${ }^{8}$

\footnotetext{
${ }^{1}$ Department of Physiology, University of Turku, Kinamyllynkatu 10, Turku FIN-20520, Finland; ${ }^{2}$ Department of Pediatrics, University of Turku, Kiinamyllynkatu 10, Turku FIN-20520, Finland; ${ }^{3}$ INRA-CNRS-Haras Nationaux-Université de Tours Joint Research Unit for Reproductive and Behavioural Physiology, Tours Research Centre, Nouzilly 3780, France; ${ }^{4}$ Department of Surgery and Cancer, Imperial College London, Hammersmith Campus, London W12 0NN, UK and ${ }^{5}$ Biotechnology Department, College of Graduate Studies, Arabian Gulf University, PO BOX 26670 Manama, Bahrain

${ }^{*}$ Corresponding author: J Toppari, Departments of Pediatrics and Physiology, University of Turku, Kiinamyllynkatu 10, FIN-20520 Turku, Finland. Tel: +358 23337579 ; E-mail: jorma.toppari@utu.fi

${ }^{6}$ These authors contributed equally to this work.

Keywords: spermatogenesis; Sertoli cells; retinoblastoma protein (RB); E2F3 transcription factor; differentiation

Abbreviations: $\mathrm{AMH}$, anti-Müllerian hormone; BrdU, 5-bromo-2'-deoxyuridine; BTB, blood-testis barrier; ES, ectoplasmic specialization; FSH, follicle-stimulating hormone; LH, luteinizing hormone; MCM, minichromosome maintenance complex; PND, postnatal day; pATM, phosphorylated ataxia telangiectasia mutated; p107, retinoblastoma-like protein p107; p130, retinoblastoma-like protein p130; RB, retinoblastoma protein; SC, Sertoli cell; shRNA, short-hairpin RNA; TJ, tight junction; TUNEL, terminal deoxynucleotidyl transferase nick-end labelling; WT-1, Wilm's tumour 1

Received 18.2.14; revised 08.4.14; accepted 09.4.14; Edited by A Stephanou
} 
We generated a SC-specific $R b$ knockout mouse line (SC-RbKO) to explore the interplay between RB and the E2F transcription factors in postnatal SC. Our data regarding the phenotype confirm the earlier findings of Nalam et al. ${ }^{8}$ demonstrating that $\mathrm{RB}$ expression in $\mathrm{SC}$ is required for normal testicular development and spermatogenesis. Moreover, RB function is critical for SC maturation and differentiation. We show for the first time that E2F3 is the only E2F family member co-expressed with RB in SC and that RB interacts physically with E2F3 in mouse testis. Furthermore, in vivo silencing of testicular E2F3 ameliorates the spermatogenic defect in the SC-RbKO mice. These results suggest that RB/E2F3 pathway mediates SC maturation and cell cycle quiescence as well as survival.

\section{Results}

$\boldsymbol{R} \boldsymbol{b}$ loss in SCs leads to a progressive failure of spermatogenesis. To study the role of RB specifically in SC, we crossed $R b^{\text {flox/flox } 9,10}$ conditional mutant mice with a transgenic line expressing CRE recombinase under a SCspecific (anti-Müllerian hormone (AMH)) promoter, Amh-Cre, to delete RB in SC from E14.5 onwards; ${ }^{11}$ (Supplementary Figure $\mathrm{S} 1 \mathrm{~A})$. It has been reported that the excision of the exon 19 flanked by the loxP sites leads to a truncation of RB that is functionally equivalent to a null allele. ${ }^{9,10}$ In addition, we opted for using $\mathrm{Rb}^{\text {flox/flox }}$ mice in the study instead of $\mathrm{Rb}^{\text {null/flox }}$ to avoid possible confounding effects on the testes due to RB haploinsufficiency in the spermatogonia of the $\mathrm{Rb}^{+/-}$mice. $R b$ inactivation was confirmed by immunohistochemical (IHC) staining of CRE and RB, Wilms' tumour 1 (WT-1) was used as a SC marker (Supplementary Figure $\mathrm{S} 1 \mathrm{~B})$. In addition, the relative $R b \mathrm{mRNA}$ levels decreased significantly in the 10-12-week-old SC-RbKO (Supplementary Figure S1C). Ablation of $R b$ in SC resulted in reduced testis size (Figures 1a and b). Accessory sex organs showed no significant differences; with the exception of epididymis that decreased in size (Supplementary Table S1). The histological analysis at the ages of 4 and 10 weeks confirmed a progressive testicular phenotype: normal initiation of spermatogenesis at the age of 4 weeks, but severe disruption of spermatogenesis and disorganized seminiferous epithelium by the age of 10 weeks as confirmed by seminiferous tubule diameter measurements (Figure 1c; Supplementary Figures S2A and B). Epididymal sperm counts of 10-12-week-old SC-RbKO mice were reduced to only $5 \%$ of that in controls (Figure 1d). Light microscopy of sperm from the cauda epididymides showed that in $45 \%$ of the mutants' sperm heads were detached from the tails (Figure 1d). Histology of cauda epididymides of the mutant mice showed abundant immature germ cells (Figure 1e). The function of the few mature sperm produced was mostly normal, as 12-week-old mice could still sire healthy pups (litter size $4.6 \pm 2$ in SC-RbKO versus $9.2 \pm 0.8$ pups/litter in WT). However, by the age of 24 weeks all SC-RbKO male mice were infertile (litter size $0 \pm 0$ in SC-RbKO versus $7.8 \pm 1.3 \mathrm{pups} /$ litter in WT). Already at the age of 20 weeks, the most advanced germ cells seen in the SC-RbKO testes were meiotic cells, and the majority of the seminiferous tubules exhibited a SC-only phenotype (Supplementary Figures S2A). a

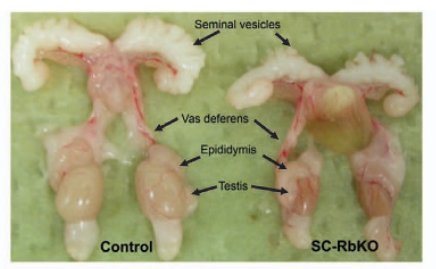

b

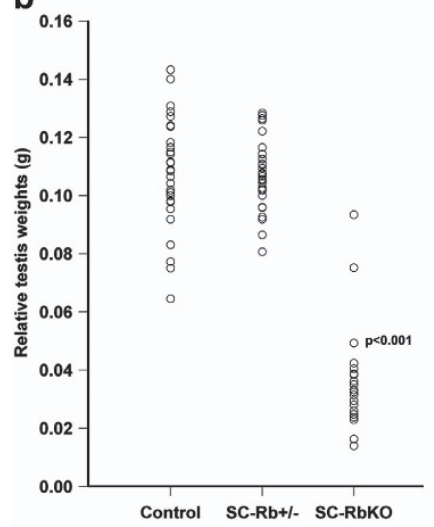

C

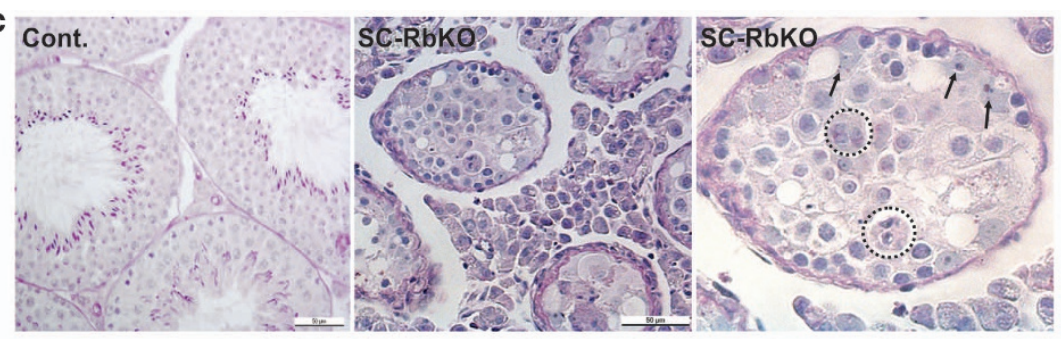

d

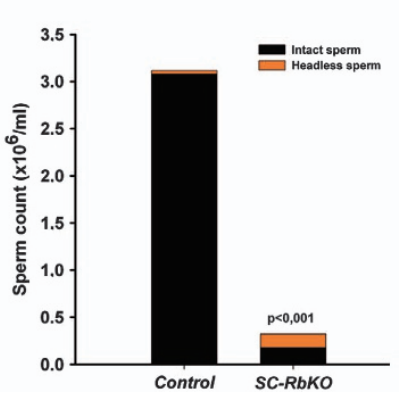

e

Control

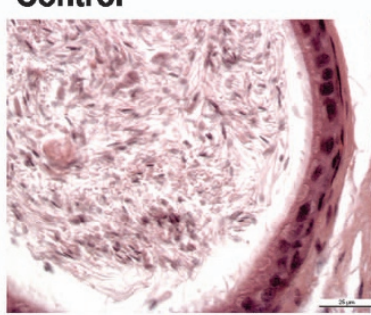

SC-RbKO

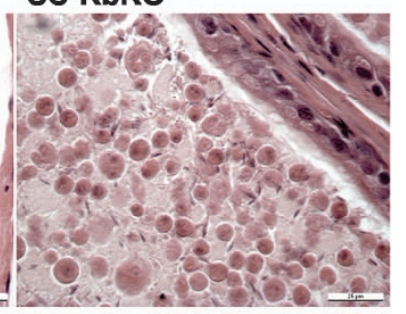

Figure $1 \mathrm{RB}$ loss in SC leads to spermatogenic failure in adult mice. (a) Reproductive tracts of 10-week-old control and SC-specific Rb knockout (SC-RbKO) male mice showing gross atrophy of SC-RbKO testes. (b) A significant reduction in relative testis weights of SC-RbKO 10-12-week-old mice in comparison with control and SC-Rb ${ }^{+1-}$ testes. (c) Testis sections from control and SC-RbKO mice (10-week old) stained with PAS. Round spermatids in symplasts, dashed black circles; SCs, black arrows. Scale bars, 50 and $25 \mu \mathrm{m}$. (d) Cauda epididymal sperm counts from 10-12-week-old SC-RbKO versus control mice showing a significant decrease of sperm counts. In addition, $45 \%$ of the sperm are headless in SC-RbKO. Error bars, S.E.M.; $P<0.05, P<0.001$. (e) H\&E staining showing control cauda epididymis full of spermatozoa (10-week old). In the SC-RbKO epididymis, there are numerous exfoliated immature germ cells and the mature sperm are less abundant. Scale bar, $25 \mu \mathrm{m}$ 
Serum luteinizing hormone ( $\mathrm{LH}$ ) or testosterone levels were not significantly different between 10-week-old control and SC-RbKO mice (Supplementary Table S2), indicating normal Leydig cell function. However, the follicle-stimulating hormone (FSH) levels were increased significantly, reflecting disturbed SC function.

Increased apoptosis and aberrant proliferation of SC in adult SC-RbKO testes. We used TUNEL (terminal deoxynucleotidyl transferase nick-end labelling) assay to examine the rate of apoptosis, the frequency of TUNELpositive germ cells was significantly increased in 6-week-old SC-RbKO testes, and this was further exacerbated in 10week-old mice (Figure 2a). At this time point, a portion of the mutant SC was also TUNEL positive (Figure 2a). We observed a perinuclear staining of phosphorylated ataxia telangiectasia mutated (pATM), an integral component of the DNA damage response, in early spermatocytes and SC in the control testes. However, a clear nuclear staining of pATM foci was detected in SC in the SC-RbKO testes (Figure $2 b$, right panels), a pattern similar to that observed in mouse SC after testicular irradiation. ${ }^{12}$ Analyses of the proliferative activity of SC in SC-RbKO testes at postnatal days (PNDs) 7 , 15 , and 30 showed a significant increase in the 5-bromo2-deoxyuridine (BrdU)-positive SC at PND30 in SC-RbKO testes (Figure $2 b$, left panels), whereas the proliferation rate of the juvenile SC remained unaffected in SC-RbKO (Figure 2c). Furthermore, the SC of 12-week-old mutant mice expressed cytokeratin 18, a marker of immature fetal $\mathrm{SC}^{6}{ }^{6}$ (Figure $2 \mathrm{~b}$, middle panels).

To determine whether the BTB is morphologically disrupted, we investigated the expression and distribution pattern of espin (an ectoplasmic specialization (basal ES) marker ${ }^{13}$ ) and claudin-11 (a tight junction (TJ) marker ${ }^{14}$ ). TJ and ES, which connect adjacent SCs, appeared to form normally in the 6-week-old SC-RbKO testes but became uncoupled in 12-week-old mutant mice (Supplementary Figure S3).

\section{Expression of DNA damage and cell organization-related} genes is already altered in juvenile SCRbKO testes. We performed a gene microarray analysis between control and SC-RbKO testis at PND10 (GEO accession no. GSE22234). At this age, the confounding effect caused by difference in tissue composition was avoided, and the number of SC was identical in both groups (Supplementary Figure S4A).

Out of a total of 114 genes with significant differences in expression; there were 32 downregulated and 82 upregulated genes in SC-RbKO testes. We analysed the complete gene list with QIAGEN's Ingenuity Pathway Analysis (IPA, QIAGEN, Redwood City, CA, USA; www.qiagen.com/ingenuity). The most relevant molecular and cellular functions were: cellular assembly and organization, cellular growth and proliferation, cell death, and cell cycle (Supplementary Figure S4C). In our study, the major canonical pathways represented by the differentially expressed genes included lysine degradation (Aldh1a2, Ide, Pappa), protein kinase A signalling (Pde4b), cell adhesion and fibrosis (Col1a1, Col8a2, Edn1), ATM signalling and DNA-damage response (Chek1), cancer signalling and aryl hydrocarbon receptor signalling (Aldh1a2,

\begin{tabular}{ccccc}
\hline $\mathbf{a}$ & & Control & SC-RbKO & p-value \\
\hline $\mathbf{6} \mathbf{w k}$ & apoptotic cells/tubule & $0.3 \pm 0.2$ & $1.85 \pm 0.2$ & $\mathrm{P}=0.006$ \\
& apoptotic SCs/tubule & 0 & 0 & \\
\hline $\mathbf{1 0} \mathbf{w k}$ & apoptotic cells/tubule & $0.2 \pm 0.01$ & $1.7 \pm 0.2$ & $\mathrm{P}=0.003$ \\
& apoptotic SCs/tubule & 0 & $0.25 \pm 0.07$ & $\mathrm{P}=0.031$ \\
\hline
\end{tabular}
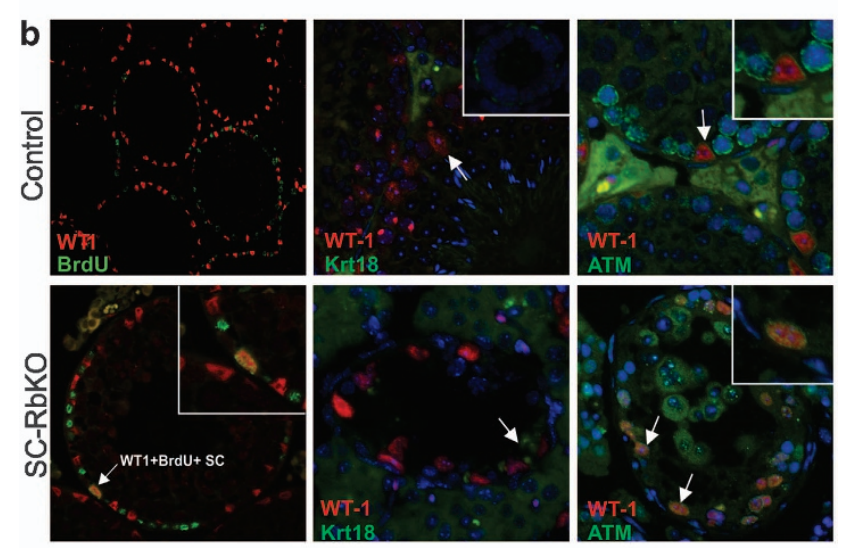

C

\begin{tabular}{ccccc}
\multicolumn{6}{c}{$\%$ of proliferating Sertoli cells } & \\
\hline Age & Control & SC-Rb+/- & SC-RbKO & p-value \\
\hline PND7 & $19.87 \pm 1.06$ & $18.63 \pm 3.75$ & $17.28 \pm 1.83$ & \\
PND15 & $0.22 \pm 0.09$ & $0.10 \pm 0.06$ & $0.25 \pm 0.10$ & \\
PND30 & $0.12 \pm 0.06$ & $0.17 \pm 0.05$ & $1.37 \pm 0.22$ & p $<0.005$ \\
\hline
\end{tabular}

Figure 2 Loss of RB results in apoptosis of germ cell and SCs and re-entry of SCs to mitotic cell cycle. (a) Quantification of apoptotic germ cells (intratubular cells positive for TUNEL only) and SCs (intratubular cells positive for both WT1 and TUNEL) in control and SC-RbKO testes at the ages of 6 and 10 weeks. ( $n=$ 4/group). Increased germ cell apoptosis was detected already at the age of 6 weeks in the SC-RbKO testes, and by the age of 10 weeks also the SC begin to undergo apoptosis in the SC-RbKO. (b) Left panels: Analysis of BrdU incorporation was performed in control (upper) and SC-RbKO (lower) testes at PND30. Double immunofluorescence labelling of WT-1 (red) and BrdU (green) revealed that a significant number of adult RB-deficient SCs maintain DNA synthesis (inset). Middle panels: Double immunofluorescent labelling of cytokeratin 18 (Krt18, green) and WT-1 (red) in testes from control and SC-RbKO mice (12-week old). Positive staining of Krt18, a marker of immature SCs, in RbKO-SCs (WT-1 +). Inset: Krt18 in PND1 mouse testis, positive control. Permeabilization in TE buffer produces unspecific signal in the sex body of the round spermatids. Right panels: Double immunofluorescence labelling of phosphorylated-ATM (pATM, green) and WT-1 (red) in testes from control and SC-RbKO mice (12-week old). In the wild-type SC nuclei, phospho-ATM is in the perinuclear area, whereas in the SC-RbKO SC PATM signal is localized to the nucleus. Inset: close-up on pATM + SC. Magnifications are $\times 200$ and $\times 00$. (c) Quantification of proliferating SCs $($ WT1 $+/$ BrdU +$)$ in mice testes shows comparable proliferative rate of WT and SC-RbKO SC during the normal proliferative time window but a cell-cycle re-entry at the PND30 in the SC-RbKO SCs ( $n=4 /$ group)

Chk1, Rb1), and BRCA1 in DNA damage response (Chk1, $R b 1)$. Validation of the array results was performed by quantitative RT-PCR (qPCR) on selected gene transcripts (Supplementary Figure S5A). The significant differences in expression between SC-RbKO and control testes further suggest that normal SC function is dependent on RB function also during early puberty. When we compared our microarray data (PND10 SC-RbKO) to the gene list from the microarray gene expression analysis of the 6-week-old Rb cKO SC from Nalam et al., ${ }^{8}$ we found that a small subset of genes was altered in both arrays: genes encoding transcription factors (Egr3, Mcm2, and Mcm6), and transmembrane proteins (Scara3, Tmem98, and VIdr) (Supplementary Figure S4B). 
RB interacts with E2F3 during testicular development. Given the important role of E2Fs in the RB pathway, we studied whether the E2F transcription factors were expressed in the same cell types within the seminiferous epithelium as RB. We found that E2F3 was the only E2F member found to be expressed in same cell types as RB in the adult mouse testis, that is, spermatogonia, preleptotene spermatocytes, and SC (Figure 3a). The expression levels of E2f1 and E2f2 mRNA displayed no significant difference between control and SC-RbKO testes (Supplementary Figure S6). E2f4 and E2f5 mRNA expression decreased in adult SC-RbKO testes that may reflect the loss of the differentiated haploid spermatids (Supplementary Figure S6). ${ }^{15}$ However, the E2f3 transcripts were highly expressed in the whole testes of mutant animals at the age of 10-12 weeks (Figure $3 \mathrm{~b}$ ) that coincided with a strong nuclear E2F3 staining of SC in IHC (Figure 3a).

The E2f3 gene encodes two protein products, E2F3a and $\mathrm{E} 2 \mathrm{~F} 3 \mathrm{~b}$, through the usage of alternative promoters. Both isoforms were detected in WT and SC-RbKO testes (Figure 3c). RB and E2F3 interact physically during testicular development as demonstrated by co-immunoprecipitation from both PND10 and PND40 wild-type mouse testes (Figure 3d). Conversely, RB/E2F3 immunoprecipitation complexes could only be faintly detected in the SC-RbKO testes.

We next examined whether there is an evidence for functional redundancy between the RB family members in the SC-RbKO testes. In the wild-type adult mouse testis, the RBs p130 and p107 were differentially expressed in a cell type-specific manner (Supplementary Figure S1B and Figures $4 a$ and b). As mentioned above, RB was detected in SC, mitotically dividing spermatogonia and preleptotene spermatocytes. In the wild-type testis, p107 was expressed exclusively in meiotic spermatocytes. However, in the 12-week-old SC-RbKO testis ectopic p107 expression was detected in a proportion of the SC, in addition to the spermatocytes (Figure 4a). Expression of p130 was detected in SC in both SC-RbKO and WT mice (Figure 4b). Both p107 and p130 mRNA levels decreased significantly in the 10-week-old SC-RbKO testes (Figures 4c and d).

The association of $\mathrm{p} 107$ and $\mathrm{p} 130$ with $\mathrm{E} 2 \mathrm{~F} 3$ was examined in parallel with the detection of RB from the E2F3 immunoprecipitates. In the juvenile PND10 testis where SCs proliferate actively, there was no evidence of E2F3 interaction with p107 or p130; this applied also to the PND40 wild-type testis. However, in PND40 SC-RbKO testes both p107 and p130 formed complexes with E2F3 (Figure 3d).

In vivo silencing of E2F3 induces a partial rescue of the spermatogenesis defect in SC-RbKO testes. To study the significance of E2F3 in the SC-RbKO phenotype, a shorthairpin RNA (shRNA) plasmid against E2F3 (shRNA-E2F3), carrying eGFP as a reporter gene, was transfected in vivo via rete testis of PND15 SC-RbKO mice. In each treated animal, one testis was injected with the shRNA-E2F3 and the other with an empty plasmid carrying only eGFP. The efficiency of the shRNA-E2F3 was confirmed in TM4 SC line in vitro (Supplementary Figure S7). Successful shRNA plasmid delivery was analysed 10 weeks after microinjection by fluorescent stereomicroscope of transfected testes (Figure 5b). A significant recovery of weight was observed in the shRNA-E2F3-transfected testes (Figure 5a), to $60 \%$ of controls. The weights of the mock transfected (eGFP plasmid) or untreated SC-RbKO testes remained both approximately $30 \%$ of control testes. At the histological level, we could also show evidence that the spermatogenic failure caused by RB deficiency in SC was partially rescued by silencing E2F3: a portion of the tubule cross-sections displayed an almost normal thickness of the seminiferous epithelium and contained mature elongated spermatids (Figure $5 \mathrm{c}$ ). We could also observe that the treatment led to the restoration of the normal organization of ES and BTB in 10-week-old mutant testes (Figure 5d).

\section{Discussion}

This study confirms the essential role of $\mathrm{RB}$ protein in supporting the function of the somatic compartment in mouse seminiferous epithelium. SC cells have an important role during testicular development and initiation of spermatogenesis in juvenile mice, but these steps appear unaffected in the SC-RbKO testes. In the juvenile mouse testes, SC proliferate to achieve the SC pool required for adult spermatogenesis. The proliferation rate during the normal proliferative time window (PND10-15) was comparable in the SC-RbKO and control animals. Instead, the decline of the SC proliferation that takes place after PND17 in the mouse, ${ }^{6,16}$ before the terminal differentiation commences, was affected by the absence of RB. A significant proportion of SC resumed proliferation at PND30, which suggests a defect in the cell cycle exit and terminal maturation of SC. However, in the continuously proliferating spermatogonia, RB has been shown to control the maintenance of spermatogonial stem cell population, as prenatal deletion of RB in germ cells leads to a transient increase in the proliferation of the undifferentiated spermatogonia and infertility as a result of a gradual exhaustion of the stem cell pool. ${ }^{17}$

Apart from minor differences in timing of the progressive phenotype, our results are in close agreement with the findings of Nalam et al. ${ }^{8}$ Despite the morphologically normal first wave of spermatogenesis in our model, the misregulation of gene expression was already apparent at PND10, suggesting that SC function was already compromised at this stage. The affected genes included the ones involved in important cellular processes, such as growth and proliferation, cell death, cell cycle and DNA damage responses. Interestingly, a small subgroup of genes encoding transcription factors and transmembrane proteins was altered in both the 6-week-old Rb cKO SC ${ }^{8}$ and PND10 SC-RbKO testes. A sustained upregulation from puberty to adulthood of the minichromosome maintenance deficit 2 and 6 (Mcm2 and Mcm6), members of the eukaryotic DNA helicase complex (reviewed in Sterner et al. ${ }^{18}$ ), reflects the importance of RB in the control of DNA replication in SC. Indeed, RB has been shown to directly interact with minichromosome maintenance complex 7 (MCM7), a subunit of the MCM complex, via its amino-terminal end to inhibit DNA replication. ${ }^{18}$ This could imply that RB acts as a major gatekeeper of SC proliferation during puberty and during the onset of terminal differentiation. 
a

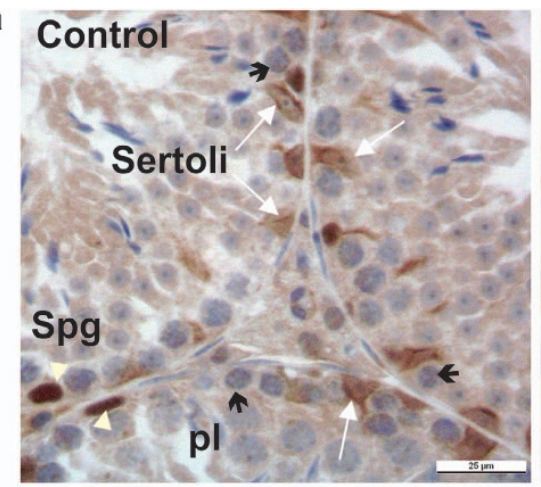

b

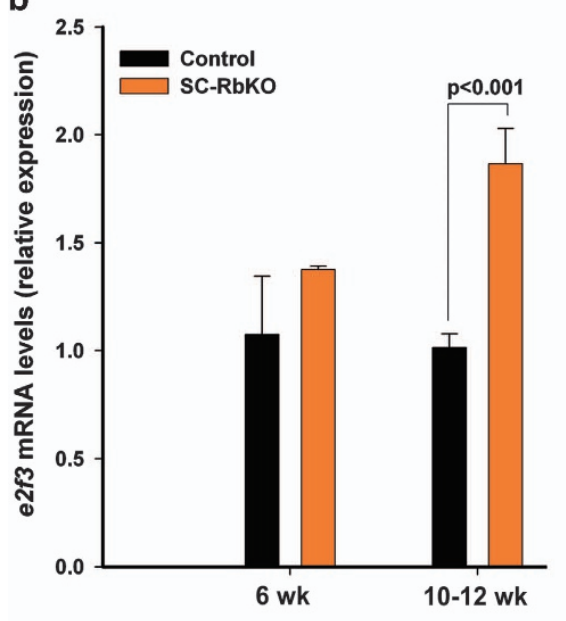

d

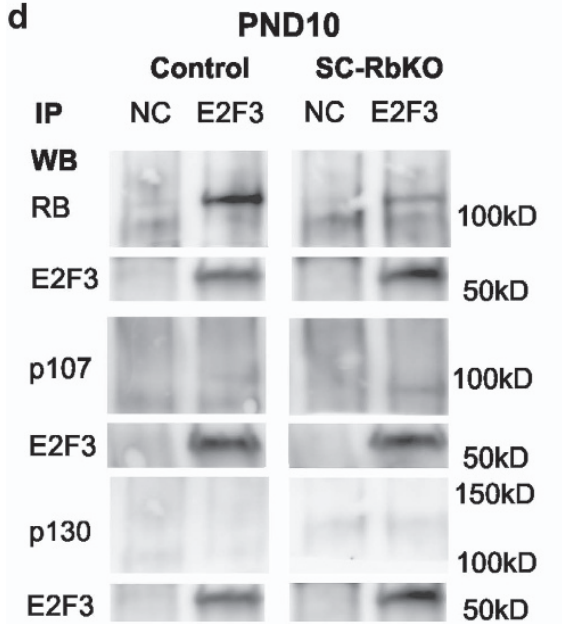

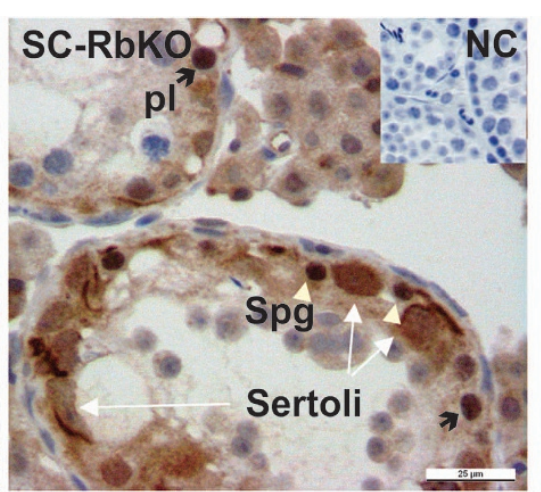

c

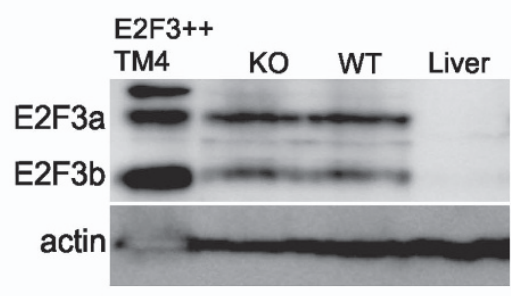

Figure 3 E2F3 in mouse SCs is developmentally controlled by the RB family. (a) Immunolocalization of E2F3 in SC (white arrows), preleptotene spermatocytes (black arrowheads), and spermatogonia (Spg, white arrowheads) of adult control and SC-RbKO mice. NC: negative control, secondary antibody only. Scale bar, $25 \mu \mathrm{m}$. (b) mRNA levels of E2f3 in control and SC-RbKO mice testes at 6 and 10-12 weeks of age relative to housekeeping genes (L19 and Ppia) and normalized to the control group. (c) Both E2F3 isoforms $a$ and $b$ are expressed at high levels in 10-12-week-old control (WT) and KO testes. E2F3 + + TM4; E2F3-overexpressing TM4 mouse-SC line (positive control); liver, negative control. (d) Co-immunoprecipitation using E2F3 antibody from whole-testis lysate from PND10 and PND40 control and SC-RbKO mice. WB analysis of RB family members shows that E2F3 interacts with RB at PND10 in the wild-type testes. Following RB deletion, E2F3 forms complexes with both p107 and p130 in the PND40 SC-RbKO testes. NC: negative control is immunoprecipitation with the same E2F3 antibody in the presence of a specific blocking peptide (sc-878 P)

SC differentiation coincides with the formation of the BTB and specialized junctions between SC and germ cells ${ }^{19}$ that maintain the structural integrity of the seminiferous epithelium. The accumulating disorganization of the SC cytoarchitecture and loss of BTB integrity and polarity as SC-RbKO mice mature coincides with the dedifferentiation of $\mathrm{SC}$. Dedifferentiation is accompanied by the induction of DNA damage resulting in activation of DNA-damage repair protein 

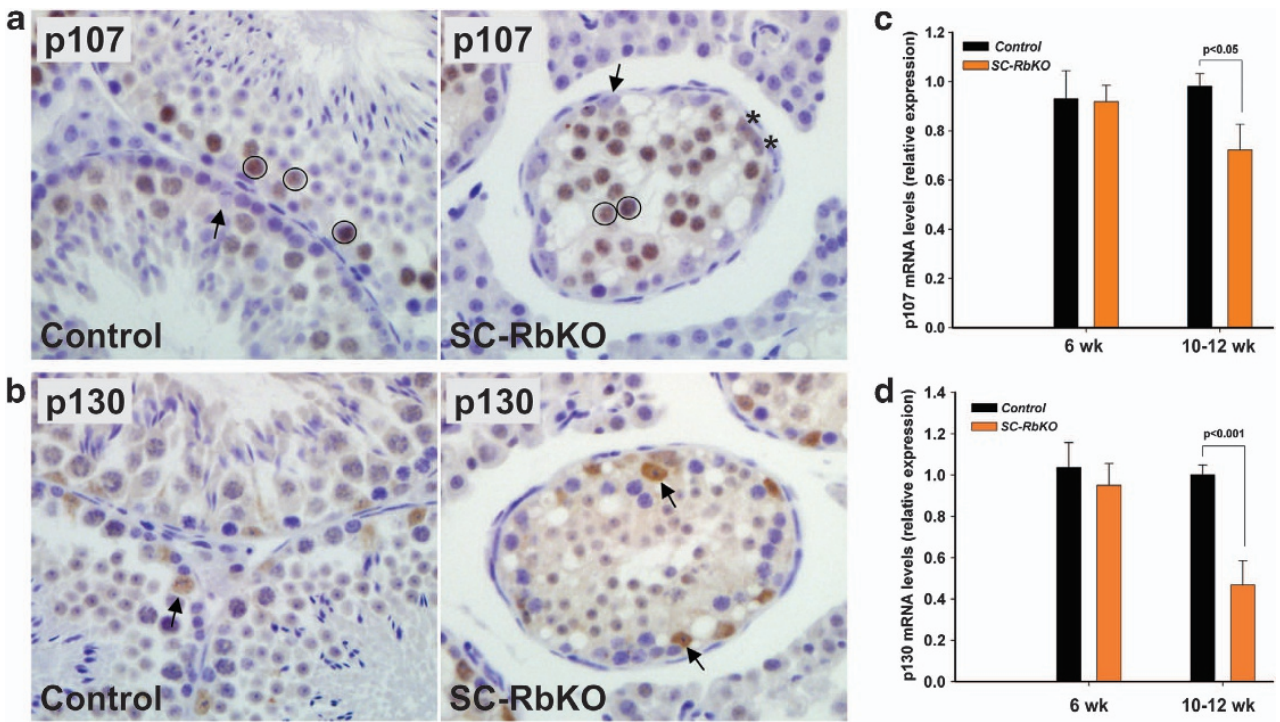

Figure 4 Expression patterns of RB family members p107 and p130 in the WT and SC-RbKO testes. (a) p107 was detected only in pachytene spermatocytes in 12-week-old control testes; however, in SC-RbKO mouse testes positive p107 signal was also detected in a proportion of SC. SCs, black arrowheads; pachytene spermatocytes, black circles. SCs with p107 signal, asterisk. (b) p130 was detected in SC, in both control and SC-RbKO mouse testes. SCs, black arrowheads. (c and d) p130 and p107 mRNA levels in SC-RbKO testes versus control at the ages of 6 and 10-12 weeks. $n=4 /$ group

and apoptosis of SC. The replicative stress is present already in the juvenile SC, as among the most relevant cellular functions altered already at PND10 were cellular proliferation, cell death, and cell cycle according to the array. Nevertheless, the majority of the SC are sustained for a long period thereafter. The expression of DNA-damage repair proteins such as phosphorylated ATM (Hamer et al. ${ }^{12}$ and our results), PARP1, and phosphorylated $X R C C 1^{20}$ may protect SC from an immediate apoptosis upon cell cycle exit.

$\mathrm{RB}$ has a well-characterized role in the regulation of the $\mathrm{E} 2 \mathrm{~F}$ family of transcription factors to control cell cycle and other cellular processes. In this report, we show that E2F3 is the only E2F family member co-expressed with RB in SCs. E2F3 is highly expressed in both control and SC-RbKO testes, and $\mathrm{E} 2 \mathrm{Fa}$ is the dominant isoform. E2F3a together with E2F1 and E2F2 have been considered transcription activators, which usually accumulate in late $\mathrm{G} 1$ phase and regulate genes that control the $\mathrm{G} 1$ to $S$ transition. The other E2F family members: E2F3b, E2F4, E2F5, E2F6, E2F7, and E2F8 function as transcriptional repressors. ${ }^{21}$ E2Fs are commonly upregulated in tumour cells, and expression of E2F3 in the absence of RB correlates with tumour proliferation. ${ }^{22}$ E2F3 has functions beyond cell cycle control, ${ }^{23}$ and increased level of E2F3 in the absence of RB can result in either apoptosis or cell proliferation $^{24}$ depending on the cell type. Here we show that $\mathrm{RB}$ and E2F3 form complexes in juvenile testes. The reduced RB signal in the SC-RbKO testes at all time points suggests that a considerable proportion of the immune-precipitated complexes found in control testes originates from SC. Conspicuously, the differences in the western blotting signal intensity at PND10 versus PND40 testes reflects a dilution of the SC- and spermatogonia-specific signal in the adult testes with a full spermatogenesis. Hence, the absence of RB/E2F3 interaction at PND40 in the co-immunoprecipitation study may also be a false negative caused by limited WB sensitivity.
Coexpression of both RB and E2F3 in both juvenile and adult SC point towards the hypothesis that the E2F3 mediates the SC-RbKO phenotype. Concordantly, ectopic expression of E2f3a in keratinocytes induces DSBs, ATM activation and the ATM-dependent apoptosis, ${ }^{25}$ which are some of the severe late SC abnormalities found in the SC-RbKO mice.

Of the other retinoblastoma family members, p130 was expressed in SCs irrespective of their RB expression, whereas ectopic $p 107$ expression was induced in a proportion of the SC upon RB loss. This induction seems to reflect an attempt to compensate for RB loss in the control of E2F3 and its responsive genes. Although, it could also result from a failure of p107 repression that drives the SC to S phase, ${ }^{26}$ or merely be a consequence of the cell cycle re-entry, as p107 accumulates in proliferating cells. ${ }^{27}$ Interestingly, an inactivation of all the RB family members and p53 by the SV40 oncogene in SC precursors of AMH/SV40 T transgenic mice leads to the development of mixed somatic Sertoli-Leydig cell tumours. ${ }^{28}$ The absence of tumour development and persistence of the SC population in the SC-RbKO may be achieved via compensation of tumour-suppressive RB action by $\mathrm{p} 107$ and $\mathrm{p} 130$.

The RB family members exhibit a preferential E2F binding pattern in physiological conditions: RB interacts with E2Fs 1-4, p107 with E2F4, and p130 with E2Fs 4 and5. ${ }^{29-31}$ It has been reported that in the absence of RB, the other RB family members may promiscuously bind the activator E2Fs. ${ }^{21}$ Indeed, in the PND40 SC-RbKO both p107 and p130 complex with E2F3, highlighting the importance of tight control of E2F3 during SC differentiation that is usually performed by RB. To our surprise, this strong association between RB with E2F3 was also observed in the juvenile SCs. The conventional activator E2Fs have been shown to have a dual function in vivo. The activator E2Fs act as transcriptional enhancers in actively proliferating progenitor cells. But, as the cells exit cell 
a

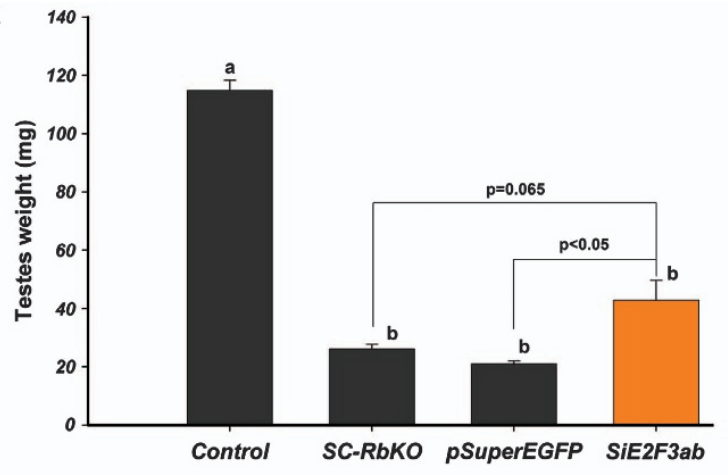

C

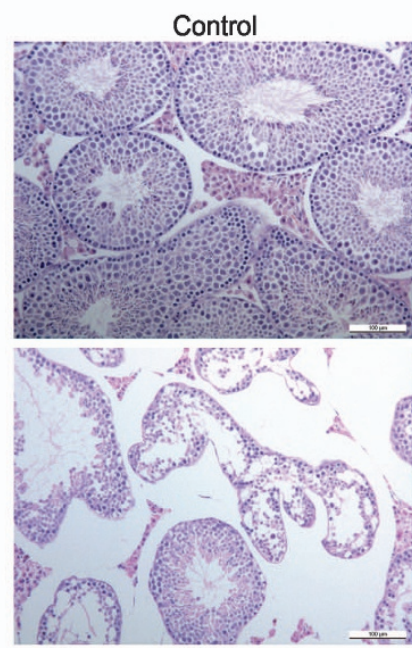

\#1, KO/SiE2F3ab

SC-RbKO b

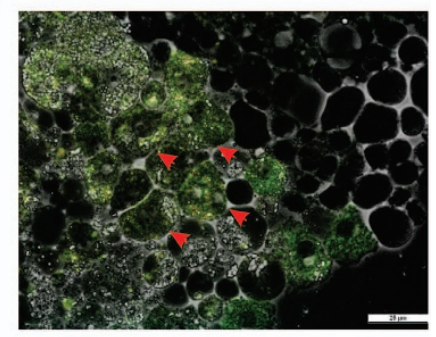

d

Control
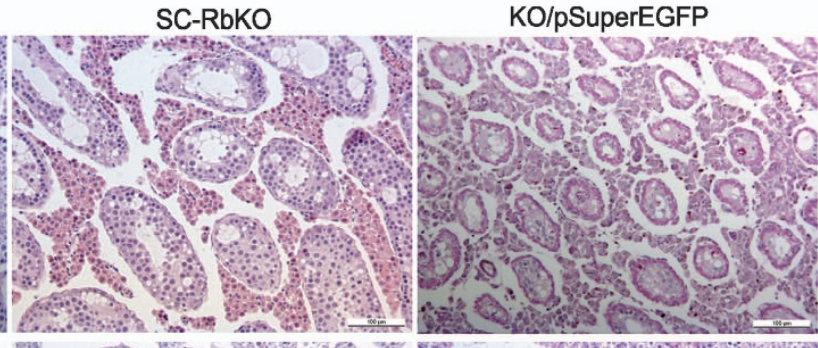

uperEGFP

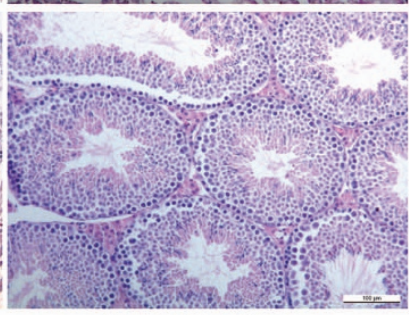

\#3, KO/SiE2F3ab

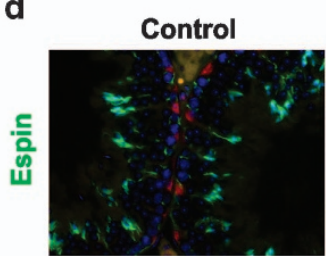

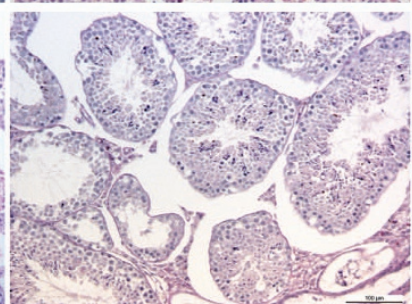

\#2, KO/SiE2F3ab
\#2, KO/SiE2F3ab
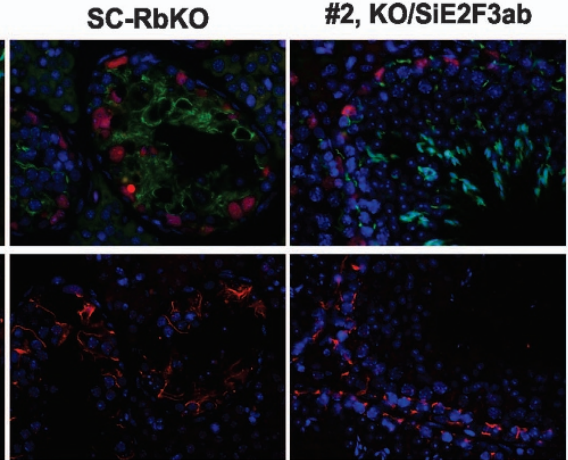

Figure 5 Partial rescue of spermatogenesis in SC-RbKO mouse testes following in vivo E2F3 silencing. (a) A significant recovery of testis weight following in vivo knockdown of E2F3ab in the 12-week-old SC-RbKO testes. Control: non-transfected WT testis, SC-RbKO: non-transfected mutant, pSuperEGFP: mutant transfected with empty pSUPER.gfp/neo plasmid, SiE2F3ab: mutant transfected with shRNA-E2F3ab plasmid. Values are mean \pm S.E.M. of $n=4$. (b) GFP expression introduced by the in vivo transfection was confirmed 10 weeks after injection by a squash preparation of seminiferous tubule segment under fluorescence microscopy containing transfected SCs (red arrowhead). (c) H\&E staining revealed normal spermatogenesis in control mouse testes at the age of 12 weeks (upper left panel) and disorganized seminiferous tubules in testes from SC-RbKO (upper middle panel) and SC-RbKO-transfected with control plasmid (KO/pSuperEGFP) at the same age (upper right panel). Testicular sections of SC-RbKO mice transfected with shRNA-E2F3ab plasmid (lower panels) show elongated spermatids and a restored seminiferous tubule architecture. (d) Testis architecture, ectoplasmic specializations (espin: green, left panels) and tight junctions (claudin11: red, right panels) were restored in SC-RbKO after knockdown of E2F3 (Magnification $\times 400)$

cycle and become terminally differentiated, they acquire the role of a transcriptional repressor together in complex with RB to block the transcription of the same target genes that were activated in the progenitors. ${ }^{32}$ As summarized in a hypothetical model in Figure 6, a fine tuning is required in the dynamics of the RBs and E2F3 in the control of gene expression during the complex process of SC differentiation.

A number of differentiation defects induced by RB loss in other cell types have been previously rescued by crossing to knockouts of activator E2Fs. For instance, in the murine retina 


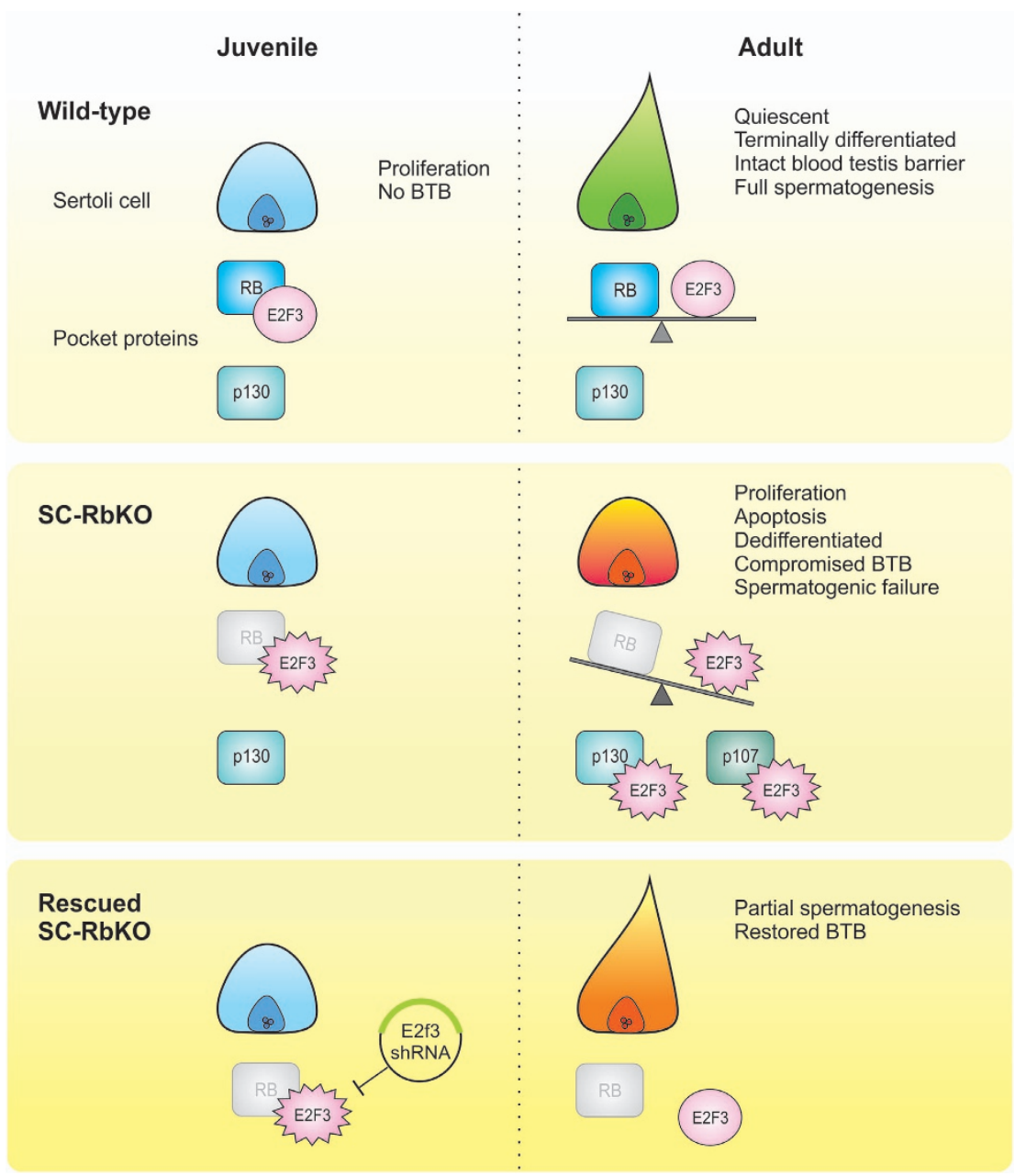

Figure 6 Hypothetical model of the RB family and E2F3 dynamics during mouse SC development. Wild-type: In the juvenile mouse SC, which are actively proliferating and have not yet formed an intact BTB, RB and E2F3 interact physically, to either activate or repress E2F3-mediated gene expression. In the terminally differentiated SCs, there is a tightly regulated balance of RB and E2F3 action. The RB family member p130 is expressed in wild-type SC in addition to RB. SC-RbKO: The juvenile SC proliferate normally and exhibit no apparent phenotype beyond altered gene expression profile in the absence of RB. Neither RB nor p130 interact with E2F3 in the juvenile SC-RbKO SC. The adult SC-RbKO SC gradually resume proliferation, become dedifferentiated, apoptotic, and fail to support spermatogenesis. Simultaneously, SC-RbKO SC assume an ectopic expression of the RB family member p107, and p107 and p130 both begin to interact with E2F3; possibly attempting to suppress a deregulated E2F3 action. Rescued SC-RbKO: E2F3 was knocked down in vivo using a shRNA in PND15 SC-RbKO testes to assess the contribution of E2F3 to the SC-RbKO phenotype. This resulted in partial rescue of the SC-RbKO phenotype with a patchy restoration of spermatogenesis and seminiferous tubule architecture

and telencephalon, deletion of E2f1 or E2f3 reverse the induction of ectopic divisions, cell death, and defects in terminal differentiation produced by deletion of $R b$ (reviewed in Talluri et al. ${ }^{33}$ ). By silencing E2F3 in the SC of the SC-RbKO in vivo to avoid possible confounding effects of E2F3 inactivation already in early juvenile SC, we achieved a partial rescue of the testicular cytoarchitecture and a patchy restoration of spermatogenesis in SC-RbKO testes. The incomplete recovery is due to limitations of in vivo transfection as well as mechanical stress resulting in partial fibrosis, which limits the extent of conclusions that can be drawn from the rescue experiment. Future studies making use of inducible E2f3 knockout mouse models will hopefully shed light on the developmental regulation of SC by RB/E2F3 complexes. Nevertheless, our results provide evidence that E2F3 regulation by RB has an important physiological role beyond the cell cycle machinery, a phenomenon not yet reported in mouse testis.
Our data show that RB is vital for the maintenance of the terminally differentiated state of SC, and this function is at least partially mediated by its interaction with E2F3 transcription factor. Altogether this study enlightens the molecular mechanisms that govern SC maturation to functional nursing cells that are essential for sperm production and fertility.

\section{Materials and Methods}

Animals. Animals were housed under environmentally controlled conditions (12-h light/12-h darkness; temperature, $21 \pm 1^{\circ} \mathrm{C}$ ) in the animal facility of the University of Turku, Turku, Finland. They were fed mouse chow SDS RM-3 (Special Diet Service, E, Soy-free, Whitman, Essex, UK) and tap water ad libitum. All procedures were carried out according to the institutional and ethical policies of the University of Turku and approved by the local ethics committee on animal experimentation.

Generation of SC-Rb-specific knockout (SC-RbKO). We used two established transgenic mouse lines: a transgenic mouse line expressing Cre recombinase under the control of the Amh promoter, selectively in SCs

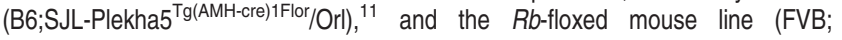


129-Rb1 ${ }^{\mathrm{tm} 2 \mathrm{Br}}$ ) (generously provided by Dr. Anton Berns, in The Netherlands Cancer Institute. ${ }^{9,10}$ To generate the SC-specific $R b$ conditional knockouts (SC$\mathrm{RbKO}$ ), transgenic Amh-Cre mice were bred with $R b$-floxed mice according to the Jackson Laboratory Technical Information Services (TIS, Bar Harbor, ME, USA) breeding scheme. Primers for genotyping PCR were for Amh-Cre: Cre26 (5'-CCTGGAAAATGCTTCTGTCCG- $3^{\prime}$ ) and Cre36 (5'-CAGGGTGTTATAAGCAA TCCC-3'), which amplify 400-bp Cre product. PCR for $R b$ floxed allele: $R b P 1$ (5'-GGCGTGTGCCCATCAATG-3') and RbP2 (5'-AACTCAAGGGAGACCTG-3') which amplify $700 \mathrm{bp}$ for $R b$-floxed allele and $650 \mathrm{bp}$ for $R b$-WT allele (Supplementary Figure S1A). All primers were designed by using the Primer3 online software. ${ }^{34,35}$

Morphological analysis of the testes and sperm count. Animals were euthanized by cervical dislocation at different time points. Age of 10-12 weeks was chosen as the focal point for most of the phenotypic studies, as a full stable adult spermatogenesis has been achieved normally in mice at this time frame. For comparative study, age-matched animals were chosen, and littermates were used whenever possible. The control group in each study consists of a mix between Cre-positive, lox-negative; Cre-negative, lox-positive, and doublenegative mice. Testes, epididymis, seminal vesicle, and prostate of SC-RbKO, $\mathrm{SC}-\mathrm{Rb}^{+1-}$ and control mice were collected immediately. Testes for histological analysis were fixed in Bouin's fixative and stained with hematoxylin and eosin (H\&E) and periodic acid-Schiff (PAS). The epididymides of SC-RbKO, $\mathrm{SC}-\mathrm{Rb}^{+/-}$, and SC-Rb control mice were isolated, rinsed with saline solution, and weighted. The sperm were released from cauda epididymides into KSOM-AA medium (cat. no. MR-121, specialty media, Millipore, Phillipsburg, NJ, USA) by applying pressure with forceps. After removal, the sperm were incubated at $37^{\circ} \mathrm{C}$ for $15 \mathrm{~min}$. The number of spermatozoa was counted under a microscope (Olympus CK 2, Olympus, Tokyo, Japan) using the Bürker chamber. Sperm smears were stained with the Papanicolaou stain for morphological analysis.

IHC and immunofluorescence. IHC and immunofluorescence were conducted on $4 \%$ paraformaldehyde-fixed paraffin-embedded tissue sections. Vectastain Elite kit (Vector Laboratories, Inc., Burlingame, CA, USA) was used for $\mathrm{IHC}$ according to the instructions of the provider. Standard immunofluorence using AlexaFluor goat secondary antibodies was performed. Primary antibodies suppliers and catalogue numbers are listed in Supplementary Table S3.

Hormone assays. Serum LH and FSH levels were measured by immunofluorometric assay (IFMA, Delfia, Wallac Oy, Turku, Finland) as described previously. ${ }^{36,37}$ The sensitivities of the LH and FSH assays were $0.03 \mu \mathrm{g} / \mathrm{l}$ in $25 \mu \mathrm{l}$ and $0.1 \mu \mathrm{g} / \mathrm{l}$, respectively. For serum testosterone determination, $25 \mu \mathrm{l}$ aliquots were used. The sera was extracted twice with $2 \mathrm{ml}$ diethyl ether and evaporated to dryness. The residues were reconstituted in PBS with $0.1 \% \mathrm{BSA}$ and measured using standard RIA, as described previously. ${ }^{38}$ The sensitivity of the assay was $1 \mathrm{fmol} / \mathrm{l}$. All serum samples were assayed at the same time using specific antiserum and radiolabelled hormones diluted the same day.

TUNEL assay. Evaluation of apoptotic germ cells and SCs was performed by fluorescent dual TUNEL and immunofluorescent detection of WT-1. Commercially available terminal transferase and biotin-16-dUTP (Roche/Boehringer Mannheim, Penzberg, Germany) were used. Briefly, the 4\% PFA-fixed sections were deparaffinized and rehydrated. Permeabilization step was carried out in a pressure cooker in $0.1 \mathrm{M}$ citrate buffer, $\mathrm{pH} 6$. Slides were rinsed with TBS and immersed in $100 \mathrm{mM} \mathrm{NH}_{4} \mathrm{Cl}$ to block autofluorescence. Sections were incubated with the TUNEL reaction mixture for $60 \mathrm{~min}$ at $37^{\circ} \mathrm{C}$, and reaction was stopped using $300 \mathrm{mM} \mathrm{NaCl}$ and $30 \mathrm{mM}$ NaCitrate. Unspecific binding of the primary antibody was blocked with $3 \%$ BSA in TBS and primary antibody WT-1 (180, Santa Cruz Biotechnologies, Santa Cruz, CA, USA) diluted in block incubated overnight at $4{ }^{\circ} \mathrm{C}$. Next a sequential incubation of AvidinTexasRed (Vector Laboratories) and AlexaFluor488 anti-rabbit antibody was performed. DAPI was used as a nucleic counterstain. Positive control was prepared by adding $1 \mathrm{U} / \mu \mathrm{l}$ DNAse for $30 \mathrm{~min}$ at $37^{\circ} \mathrm{C}$ and from negative control terminal deoxynucleotidyl transferase (TdT) was omitted. The number of apoptotic cells per section was determined by counting intratubular TUNEL-positive cells across entire cross-sections selected at random within 6- and 12-week-old animals, and data are presented as the number of cells per square millimetre.

Cell proliferation and DNA synthesis analysis. Cell proliferation and DNA synthesis were evaluated using BrdU incorporation. We injected male mice at
PND7, PND15, and PND30 with BrdU (200 mg/kg body weight; Sigma-Aldrich, St. Louis, MO, USA) in $\mathrm{NaCl}(0.9 \%)$. After $2 \mathrm{~h}$, animals were killed, the testes and small intestine were collected and fixed in $4 \%$ PFA. ${ }^{39}$ Paraffin-embedded sections were processed as described in previously in Nurmio et al. ${ }^{40}$ for detection of BrdU and SC. The sections were examined under fluorescence microscopy (Zeiss AxioVert 200M, Carl Zeiss AG, Oberkochen, Germany). SC positive for BrdU and WT-1 were counted in 20 round cross-sections from each testis.

Western blotting analysis. Whole testes or cells from TM4 cell line were lysed in RIPA buffer at $4{ }^{\circ} \mathrm{C}$ for $30 \mathrm{~min}$. Lysates were centrifuged for $15 \mathrm{~min}$ at $10000 \times g$, and the supernatant was collected. Protein concentration measurement was conducted as described previously. ${ }^{41}$ The protein extracts were resolved through 10\% sodium dodecyl sulphate polyacrylamide gel electrophoresis (SDS-PAGE) using Mini Protean II system (Bio-Rad Laboratories, Inc. Hercules, CA, USA). Proteins were transferred onto a polyvinylidene fluoride membrane (Hybond, Amersham Pharmacia Biotech, Aylesbury, UK). The membrane was incubated in a blocking buffer ( $10 \mathrm{mM}$ Tris-HCl, pH 7.5, 0.1\% Triton-X (TBS-T), and $5 \%$ non-fat milk powder) at room temperature for at least $1 \mathrm{~h}$, followed by incubation in polyclonal rabbit anti-E2F3 antibody diluted 1: 500 in blocking buffer, at $4{ }^{\circ} \mathrm{C}$ overnight. The membrane was incubated in horseradish peroxidaseconjugated donkey anti-rabbit antibody (Amersham GE Healthcare, Buckinghamshire, UK) diluted 1:2000 in blocking buffer for $1 \mathrm{~h}$ at room temperature. ECL western blotting detection kit (Amersham GE Healthcare) was used, and the membrane was exposed to X-ray film (Fuji Rx 100, Fujifilm, Tokyo, Japan). The membranes were stripped ${ }^{7}$ and reprobed using a mouse anti-actin monoclonal antibody for normalization of the loading. Primary antibody suppliers and catalogue numbers are listed in Supplementary Table S4.

\section{Co-immunoprecipitation and western blotting analysis. Fresh} whole testes were homogenized in a non-denaturing lysis buffer $(50 \mathrm{mM}$ Tris- $\mathrm{HCl}$, $170 \mathrm{mM} \mathrm{NaCl}, 5 \mathrm{mM}$ EDTA, $1 \mathrm{mM}$ DTT, 1\% NP-40) containing protease inhibitor cocktail cOmplete, Mini (Roche). The lysates were sonicated using Bioruptor (Diagenode, Liège, Belgium) at $2 \times 30 \mathrm{~s}$. After incubation on ice, the lysates were centrifuged at for $25 \mathrm{~min} 10000 \times \mathrm{g}$. One milligram of protein was precleared using $2 \mu \mathrm{g}$ of normal rabbit $\operatorname{lgG}$ and $20 \mu \mathrm{l}$ of Dynabeads Protein $\mathrm{G}$ (Invitrogen, Carlsbad, CA, USA). The lysate was then incubated with $2 \mu \mathrm{g}$ of E2F3 C-18 antibody (sc-878, Santa Cruz) overnight at $4{ }^{\circ} \mathrm{C}$. A control sample was prepared by adding $8 \mu \mathrm{g}$ of E2F3 blocking peptide (sc-878P, Santa Cruz) to the reaction. Fifty microlitres of Dynabead Protein $G$ was used to pull down the complexes. The immunoprecipitate together with input lysate was loaded to Mini-Protean TGX 4-20\% SDS-PAGE gel (Bio-Rad). RB was detected from the upper part of the blot with mouse monoclonal anti-RB (MAB3186, Merck Millipore (Chemicon), Billerica, MA, USA), and E2F3 was detected from the lower part of the blot with E2F3 C-18 (sc-878, Santa Cruz).

RNA isolation and real-time qRT-PCR. We isolated total RNA with TRIZOL reagent (Invitrogen) from male control, SC- $\mathrm{Rb}^{+/-}$, and SC-RbKO mice. RNA was precleaned with an RNeasy MinElute Cleanup Kit (Qiagen, Valencia, CA, USA). RNA samples were then treated with DNase (DNase I Amplification Grade Kit, Invitrogen, Life Technologies, Paisley, UK). cDNA synthesis and quantitative RT-PCR were performed using the DyNAmo HS two-step SYBR Green qRT-PCR kit (Finnzymes Oy, Espoo, Finland). The data were normalized by relating gene expression to the mouse ribosomal protein $\mathrm{L} 19$ and peptidyl-prolyl isomerase A (PPIA, cyclophilin A) using Pfaffl method. Primer sequences are listed in Supplementary Table S4.

Microarray analysis. We isolated total RNA with TRIZOL reagent (Invitrogen) from PND10 male control, SC-Rb ${ }^{+1-}$, and SC-RbKO mice and precleaned them with an RNeasy MinElute Cleanup Kit (Qiagen). The RNA concentrations were measured with Nanodrop ND-1000 (Thermo Fisher Scientific, Waltham, MA, USA), and RNA quality was controlled by Experion analysis (BioRad Laboratories). All subsequent steps of the microarray analysis were carried out at the Finnish DNA-Microarray Centre utilizing the MouseWG-6 v2 Expression BeadChips (Illumina, San Diego, CA, USA), which contains over 45000 known genes, gene candidates, and splice variants. Three hundred nanograms of each RNA sample was used as a template for producing double-stranded cDNA and then biotinylated cRNA using the Illumina RNA TotalPrep Amplification Kit (Ambion Inc., Austin, TX, USA). The labelled cRNA was purified and hybridized to the BeadChip at $58^{\circ} \mathrm{C}$ for $17 \mathrm{~h}$ following the Illumina Whole-Genome Gene Expression 
Protocol for BeadStation (Illumina). Hybridization was detected with Cyanine3streptavidin (GE Healthcare, Little Chalfont, UK), and the arrays were scanned with the Illumina BeadArray Reader (Illumina). Normalization and statistical analyses of the microarray data were performed using the statistical software $R$ package limma (http://www.R-project.org) or Sigma Stat 3.1 (SPSS Inc., Chicago, IL, USA). The fold change ranging from -1.60 to +2.59 versus controls was set according to hierarchical clustering and principal component analysis.

Knockdown of E2F3 by specific shRNA silencing. For silencing the expression of E2F3 (E2F3a, E2F3b), an expression vector containing shRNA that can specifically inhibit both E2F3 gene isoforms was constructed using a previously published sequence, ${ }^{42}$ and compared it to a sequence of mouse E2F3 mRNA (NM_010093), before designing a pair of oligonucleotides (60 nt); E2F3 primers: sense primer: $5^{\prime}$-GATCCCCGACCAAACTGTTATAGTTGTTCAAGAGAC AACTATAACAGTTTGGTCTTTTTA- $3^{\prime}$ and antisense primer: $5^{\prime}$-AGCTTAAAA AGACCAAACTGTTATAGTTGTCTCTTGAACAACTATAACAGTTTGGTCGGG-3'. To generate siRNAs, equimolar amounts of complementary sense and antisense strands were annealed after boiling by slowly cooling to RT in $19 \mu \mathrm{l}$ of annealing buffer (1 M KaAc, $20 \mathrm{mM} \mathrm{MgAc}$ and $300 \mathrm{mM}$ HEPES-KOH, pH 7.4). The annealed oligos were inserted into the Bglll/Hindlll sites of pSUPER.gfp/neo vector (OligoEngine, Seattle, WA, USA) following the manufacturer's instructions. Electro-competent $E$. coli cells were transformed by shRNA-E2F3 vector or the pSUPER.gfp/neo control empty vector. All vectors were sequenced by The Finnish Microarray and Sequencing Centre (BTK Sequencing Service, Turku, Finland). Plasmids were propagated in bacteria by standard procedures and purified using a Maxiprep kit (Qiagen).

In vivo DNA transfection. Plasmid DNA was diluted with $5 \%$ glucose to the chosen concentration ( $2 \mu \mathrm{g} /$ per testis), and complexed with in vivo-jetPEI (cationic polymer transfection reagent, PolyPlus Transfection, Illkirch, France) according to the manufacturer's instructions. SC-RbKO male mice at PND15 were anesthetized with isoflurane. Testes were pulled out from the abdominal cavity, and approximately $10 \mu \mathrm{l}$ of plasmid DNA solution was injected into the rete testis using glass capillaries under a binocular microscope (Olympus SZ40, Olympus) as previously described. ${ }^{43}$ The testes were then returned to the abdominal cavity, and the abdominal wall and skin were closed with sutures. Injected animals were killed at the age of 10-12 weeks; testes were removed and fixed for histological study.

Statistical analysis. All values are presented as mean \pm S.E.M. We performed statistical analyses using the SigmaStat software (SigmaStat 3.5 for windows; SPSS Inc). $t$-Test and one-way ANOVA followed by Holm-Sidak test were used. The level of statistical significance was set as $P<0.05$.

\section{Conflict of Interest}

The authors declare no conflict of interest.

Acknowledgements. We are indebted to Dr. Anton Berns (The Netherlands Cancer Institute, Amsterdam, The Netherlands) for providing us with the floxed Rb mice. We thank Ms. Taija Poikkipuoli for assistance with histology, Jonna Palmu and Hannele Rekola for their technical assistance with genotyping PCR, Taina Kirjonen for her technical help with hormone measurements, Jouko Sandholm for helping with imaging, and Tiina Kyrölä for taking good care of the mouse colony. This work was supported financially by The Academy of Finland, The Sigrid Jusélius Foundation, The Finnish Cultural Foundation, Turku Doctoral Programme of Molecular Medicine (TuDMM), and The Turku University Hospital evo-funds.

1. Classon M, Harlow $E$. The retinoblastoma tumour suppressor in development and cancer. Nat Rev Cancer 2002; 2: 910-917.

2. Burkhart DL, Sage J. Cellular mechanisms of tumour suppression by the retinoblastoma gene. Nat Rev Cancer 2008; 8: 671-682.

3. Yan W, Kero J, Suominen J, Toppari J. Differential expression and regulation of the retinoblastoma family of proteins during testicular development and spermatogenesis: roles in the control of germ cell proliferation, differentiation and apoptosis. Oncogene 2001; 20: 1343-1356.

4. Yan W, West A, Toppari J, Lahdetie J. Stage-specific expression and phosphorylation of retinoblastoma protein (pRb) in the rat seminiferous epithelium. Mol Cell Endocrinol 1997; 132: $137-148$.
5. Clarke AR, Maandag ER, van Roon M, van der Lugt NM, van der Valk M, Hooper ML et al. Requirement for a functional Rb-1 gene in murine development. Nature 1992; 359: 328-330.

6. Sharpe RM, McKinnell C, Kivlin C, Fisher JS. Proliferation and functional maturation of Sertoli cells, and their relevance to disorders of testis function in adulthood. Reproduction 2003; 125: 769-784.

7. Skakkebaek NE, Rajpert-De Meyts E, Main KM. Testicular dysgenesis syndrome: an increasingly common developmental disorder with environmental aspects. Hum Reprod 2001; 16: 972-978.

8. Nalam RL, Andreu-Vieyra C, Braun RE, Akiyama H, Matzuk MM. Retinoblastoma protein plays multiple essential roles in the terminal differentiation of Sertoli cells. Mol Endocrinol 2009; 23: 1900-1913.

9. Marino S, Vooijs M, van Der Gulden H, Jonkers J, Berns A. Induction of medulloblastomas in p53-null mutant mice by somatic inactivation of $\mathrm{Rb}$ in the external granular layer cells of the cerebellum. Genes Dev 2000; 14: 994-1004.

10. Vooijs $M$, van der Valk M, te Riele $H$, Berns A. Flp-mediated tissue-specific inactivation of the retinoblastoma tumor suppressor gene in the mouse. Oncogene 1998; 17: 1-12.

11. Lecureuil C, Fontaine I, Crepieux P, Guillou F. Sertoli and granulosa cell-specific Cre recombinase activity in transgenic mice. Genesis 2002; 33: 114-118.

12. Hamer G, Kal HB, Westphal CH, Ashley T, de Rooij DG. Ataxia telangiectasia mutated expression and activation in the testis. Biol Reprod 2004; 70: 1206-1212.

13. Bartles JR, Wierda A, Zheng L. Identification and characterization of espin, an actin-binding protein localized to the F-actin-rich junctional plaques of Sertoli cell ectoplasmic specializations. J Cell Sci 1996; 109, Pt 6Pt 6): 1229-1239.

14. Gow A, Southwood CM, Li JS, Pariali M, Riordan GP, Brodie SE et al. CNS myelin and sertoli cell tight junction strands are absent in Osp/claudin-11 null mice. Cell 1999; 99: 649-659.

15. El-Darwish KS, Parvinen M, Toppari J. Differential expression of members of the E2F family of transcription factors in rodent testes. Reprod Biol Endocrinol 2006; 4: 63.

16. Vergouwen RP, Jacobs SG, Huiskamp R, Davids JA, de Rooij DG. Proliferative activity of gonocytes, Sertoli cells and interstitial cells during testicular development in mice. J Reprod Fertil 1991; 93: 233-243.

17. Hu YC, de Rooij DG, Page DC. Tumor suppressor gene Rb is required for self-renewal of spermatogonial stem cells in mice. Proc Natl Acad Sci USA 2013; 110: 12685-12690.

18. Sterner JM, Dew-Knight S, Musahl C, Kornbluth S, Horowitz JM. Negative regulation of DNA replication by the retinoblastoma protein is mediated by its association with MCM7. Mol Cell Biol 1998; 18: 2748-2757.

19. Kopera IA, Bilinska B, Cheng CY, Mruk DD. Sertoli-germ cell junctions in the testis: a review of recent data. Philos Trans R Soc Lond B Biol Sci 2010; 365: 1593-1605.

20. Ahmed EA, Barten-van Rijbroek AD, Kal HB, Sadri-Ardekani H, Mizrak SC, van Pelt AM et al. Proliferative activity in vitro and DNA repair indicate that adult mouse and human Sertoli cells are not terminally differentiated, quiescent cells. Biol Reprod 2009; 80: 1084-1091.

21. Chen HZ, Tsai SY, Leone G. Emerging roles of E2Fs in cancer: an exit from cell cycle control. Nat Rev Cancer 2009; 9: 785-797.

22. Hurst CD, Tomlinson DC, Williams SV, Platt FM, Knowles MA. Inactivation of the Rb pathway and overexpression of both isoforms of E2F3 are obligate events in bladder tumours with 6p22 amplification. Oncogene 2008; 27: 2716-2727.

23. McClellan KA, Ruzhynsky VA, Douda DN, Vanderluit JL, Ferguson KL, Chen D et al. Unique requirement for $\mathrm{Rb} / \mathrm{E} 2 \mathrm{~F} 3$ in neuronal migration: evidence for cell cycle-independent functions. Mol Cell Biol 2007; 27: 4825-4843.

24. Ziebold U, Reza T, Caron A, Lees JA. E2F3 contributes both to the inappropriate proliferation and to the apoptosis arising in Rb mutant embryos. Genes Dev 2001; 15 : 386-391.

25. Paulson QX, Pusapati RV, Hong S, Weaks RL, Conti CJ, Johnson DG. Transgenic expression of E2F3a causes DNA damage leading to ATM-dependent apoptosis. Oncogene 2008; 27: 4954-4961.

26. Burkhart DL, Wirt SE, Zmoos AF, Kareta MS, Sage J. Tandem E2F binding sites in the promoter of the p107 cell cycle regulator control p107 expression and its cellular functions. PLOS Genet 2010; 6: e1001003.

27. Smith EJ, Leone G, Nevins JR. Distinct mechanisms control the accumulation of the Rb-related p107 and p130 proteins during cell growth. Cell Growth Differ 1998; 9: 297-303.

28. Quintana S, Venara M, Rey R, di Clemente N, Chemes HE. Origin and evolution of somatic cell testicular tumours in transgenic mice. J Pathol 2010; 221: 443-451.

29. Lees JA, Saito M, Vidal M, Valentine M, Look T, Harlow E et al. The retinoblastoma protein binds to a family of E2F transcription factors. Mol Cell Biol 1993; 13: 7813-7825.

30. Moberg K, Starz MA, Lees JA. E2F-4 switches from p130 to p107 and pRB in response to cell cycle reentry. Mol Cell Biol 1996; 16: 1436-1449.

31. Hijmans EM, Voorhoeve PM, Beijersbergen RL, van 't Veer LJ, Bernards R. E2F-5, a new E2F family member that interacts with p130 in vivo. Mol Cell Biol 1995; 15: 3082-3089.

32. Chong JL, Wenzel PL, Saenz-Robles MT, Nair V, Ferrey A, Hagan JP et al. E2f1-3 switch from activators in progenitor cells to repressors in differentiating cells. Nature 2009; 462 : 930-934.

33. Talluri S, Isaac CE, Ahmad M, Henley SA, Francis SM, Martens AL et al. A G1 checkpoint mediated by the retinoblastoma protein that is dispensable in terminal differentiation but essential for senescence. Mol Cell Biol 2010; 30: 948-960. 
34. Untergrasser $\mathrm{A}$, Cutcutache I, Koressaar $\mathrm{T}, \mathrm{Ye} \mathrm{J}$, Faircloth $\mathrm{BC}$, Remm $\mathrm{M}$ et al. Primer3-new capabilities and interfaces. Nucleic Acids Res 2012; 40: e115.

35. Koressaar T, Remm M. Enhancements and modifications of primer design program Primer3. Bioinformatics 2007; 23: 1289-1291.

36. van Casteren Jl, Schoonen WG, Kloosterboer HJ. Development of time-resolved immunofluorometric assays for rat follicle-stimulating hormone and luteinizing hormone and application on sera of cycling rats. Biol Reprod 2000; 62: 886-894.

37. Haavisto AM, Pettersson K, Bergendahl M, Perheentupa A, Roser JF, Huhtaniemi I. A supersensitive immunofluorometric assay for rat luteinizing hormone. Endocrinology 1993; 132: 1687-1691.

38. Huhtaniemi I, Nikula H, Rannikko S. Treatment of prostatic cancer with a gonadotropin-releasing hormone agonist analog: acute and long term effects on endocrine functions of testis tissue. J Clin Endocrinol Metab 1985; 61: 698-704.

39. van de Kant HJ, de Rooij DG. Periodic acid incubation can replace hydrochloric acid hydrolysis and trypsin digestion in immunogold-silver staining of bromodeoxyuridine incorporation in plastic sections and allows the PAS reaction. Histochem J 1992; 24 170-175.

40. Nurmio M, Toppari J, Kallio J, Hou M, Soder O, Jahnukainen K. Functional in vitro model to examine cancer therapy cytotoxicity in maturing rat testis. Reprod Toxicol 2009; 27: $28-34$
41. Shan B, Zhu X, Chen PL, Durfee T, Yang Y, Sharp D et al. Molecular cloning of cellular genes encoding retinoblastoma-associated proteins: identification of a gene with properties of the transcription factor E2F. Mol Cell Biol 1992; 12: 5620-5631.

42. Smith EJ, Leone G, DeGregori J, Jakoi L, Nevins JR. The accumulation of an E2F-p130 transcriptional repressor distinguishes a G0 cell state from a G1 cell state. Mol Cell Biol 1996; 16: 6965-6976.

43. Yomogida K, Yagura Y, Nishimune Y. Electroporated transgene-rescued spermatogenesis in infertile mutant mice with a sertoli cell defect. Biol Reprod 2002; 67: 712-717.

(c) (i) $(\Theta$ Cell Death and Disease is an open-access journal published by Nature Publishing Group. This work is licensed under a Creative Commons Attribution-NonCommercialNoDerivs 3.0 Unported License. The images or other third party material in this article are included in the article's Creative Commons license, unless indicated otherwise in the credit line; if the material is not included under the Creative Commons license, users will need to obtain permission from the license holder to reproduce the material. To view a copy of this license, visit http://creativecommons.org/licenses/ by-nc-nd/3.0/

Supplementary Information accompanies this paper on Cell Death and Disease website (http://www.nature.com/cddis) 